\title{
Práticas integrativas e complementares na assistência do período puerperal
}

\author{
Integrative and complementary practices in postpartum care \\ Prácticas integradoras y complementarias en la atención pos parto
}

Roberta Conceição Ferreira ${ }^{1 *}$, Diego Nascimento de Freitas ${ }^{1}$, Tauane Letícia Pinto Zanelli ${ }^{1}$, Tatiane Montelatto Marques ${ }^{1}$, Clarice Santana Milagres ${ }^{1}$.

\section{RESUMO}

Objetivo: Identificar e averiguar como as práticas integrativas e complementares em saúde, comuns e acessíveis, podem propiciar benefícios ao binômio mãe-filho no período puerperal. Revisão Bibliográfica: $A$ atenção qualificada em saúde aplicada no pré-natal e no puerpério, são fundamentais para a saúde materna e neonatal, por haver diversas mudanças na rotina deste binômio, as PICS são opções reais para proporcionar uma assistência individualizada à puérpera ao promover ou recuperar saúde por meio da medicina alternativa. Dentre as várias terapias, a utilização de plantas medicinais e aromaterapia; a prática chinesa Lian Gong, a meditação, e a técnica de Shantala puderam ser elencadas e suas diversas formas de aplicação possibilitam uma transformação saudável e gradativa diante das diversas alterações sofridas pela mulher entre os períodos de gestação e puerpério. Considerações Finais: Os benefícios proporcionados pelas PICS à puérpera, contemplam o binômio mãe/filho e podem ser vistos por benefícios como alívio de dores, desconfortos, cansaço e disfunções orgânicas, alívio de ansiedade e tristeza, frequentes nesse período.

Palavras-chave: Terapias complementares, Saúde da mulher, Enfermagem.

\section{ABSTRACT}

Objective: To identify and find out how the integrative and complementary health practices, common and accessible, can provide benefits to the mother-child binomial in the puerperal period. Bibliographic Review: Qualified health care applied in prenatal and puerperium, are fundamental for maternal and neonatal health, as there are several changes in the routine of this binomial, PICS are real options to provide individualized assistance to the puerperal woman when promoting or regain health through alternative medicine. Among the various therapies, the use of medicinal plants and aromatherapy; the Chinese Lian Gong practice, meditation, and the Shantala technique could be listed and its various forms of application enable a healthy and gradual transformation in the face of the various changes suffered by women between the periods of pregnancy and the puerperium. Final Considerations: The benefits provided by the PICS to the puerperal woman, include the mother / child binomial and can be seen by benefits such as pain relief, discomfort, tiredness and organic dysfunctions, relief of anxiety and sadness, frequent in this period.

Keywords: Complementary therapies, Women's health, Nursing.

\section{RESUMEN}

Objetivo: Identificar y conocer cómo las prácticas de salud integradoras y complementarias, comunes y accesibles, pueden brindar beneficios al binomio madre-hijo en el período puerperal. Revisión Bibliográfica: La atención calificada aplicada en el prenatal y puerperio, son fundamentales para la salud materna y neonatal, ya que existen varios cambios en la rutina de este binomio, los PICS son opciones reales para brindar asistencia individualizada a la puérpera al momento de promover o recuperar la salud a través de la medicina alternativa. Entre las diversas terapias, el uso de plantas medicinales y aromaterapia; Se podría enumerar la práctica china del Lian Gong, la meditación y la técnica Shantala y sus diversas formas de aplicación permiten una transformación saludable y gradual ante los diversos cambios que sufre la mujer entre los períodos de embarazo y puerperio. Consideraciones Finales: Ios beneficios que brinda el PICS a la puérpera, incluyen el binomio madre / hijo y pueden verse por beneficios como alivio del dolor, malestar, cansancio y disfunciones orgánicas, alivio de la ansiedad y la tristeza, frecuentes en este período.

Palabras clave: Terapias complementarias, Salud de la mujer, Enfermería.

${ }^{1}$ Centro Universitário da Fundação Hermínio Ometto (FHO), Araras - SP. *E-mail: ro22cferreira@gmail.com 


\section{INTRODUÇÃO}

O Pacto pela Saúde (PS) de 2006 foi um dos marcos na estruturação e aplicação do SUS no país (BRASIL, 2006). O componente Pactos Pela Vida do PS definiu onze prioridades e, das quais, a redução da mortalidade infantil e materna a compuseram em um dos seus três eixos prioritários - Pactos pela Vida, de Gestão e em Defesa do Sistema Único de Saúde (SUS), que vigorou de 2007 a 2011 (BRASIL, 2007).

A saúde da mulher e da criança é um dos pilares das Políticas Públicas brasileiras, e após a promulgação da Lei $n^{\circ}$ 8080/1990, a atenção universal, equânime e integral a este binômio tornou-se notória (BRASIL, 1990). No país, o atendimento pela Atenção Primária à Saúde aumentou significativamente a cobertura do pré-natal nos últimos anos, reduzindo assim os riscos de morbimortalidade e complicações, proporcionando assim um atendimento de qualidade às mulheres nas ações referentes à saúde (CUNHA AC, et al., 2019).

A atenção qualificada em saúde aplicada no pré-natal e no puerpério são fundamentais para a saúde materna e neonatal devido às diversas mudanças na rotina deste binômio. Vale ressaltar que o objetivo da assistência pré-natal de forma humanizada é acolher a mulher desde o início da gestação, favorecendo uma gravidez saudável e um nascimento de uma criança sadia. Logo, a contribuição para garantia do bem-estar materno-neonatal se prolonga para além do período gestacional, mas também enquanto a mesma for puérpera (BRASIL, 2005).

As Portarias Ministeriais ํํ 971 em 03 de maio de 2006 e ํำ1.600, de 17 de julho de 2006 instituíram a Política Nacional de Práticas Integrativas e Complementares (PNPIC). Em 2018, como forma de atualizar tais práticas, também foi instituído o "Glossário Temático: práticas integrativas e complementares em saúde". Essas terapias utilizam recursos e técnicas baseadas em conhecimentos tradicionais, voltados para prevenir diversas doenças prevalentes na população brasileira, como depressão, hipertensão arterial, obesidade, entre outras.

Após a implementação e constante atualização desta política, o SUS passou a ofertar 29 procedimentos de práticas integrativas e complementares à população (tornando o líder mundial em oferecer esse tipo de serviço na Atenção Básica à Saúde), sendo plantas medicinais e fitoterapia; homeopatia; medicina tradicional chinesa; medicina antroposófica (antroposofia aplicada à saúde); e termalismo/crenoterapia as práticas normatizadas na PNPIC inicialmente (BRASIL, 2006; BRASIL, 2018)

As vantagens e benefícios proporcionados pelas Práticas Integrativas e Complementares em Saúde (PICS) proporcionam ao usuário, baixos custos para serem utilizadas, podem impactar na redução de despesas do município e na qualidade dos serviços prestados (BRASIL, 2006). Uma vez oferecidas, empoderam e reafirmam as práticas culturais de diferentes populações. $\mathrm{Na}$ atenção à gestante e puérpera, as PICS contribuem por auxiliá-las em seu autocuidado, bem como ao recém-nascido, amenizando sintomas indesejáveis e proporcionando bem-estar físico e mental ao binômio (VALADARES C, 2018).

Diante do exposto, este artigo tem como principal objetivo identificar e averiguar como as práticas integrativas e complementares em saúde, comuns e acessíveis, podem propiciar benefícios ao binômio mãefilho no período puerperal.

\section{REVISÃO BIBLIOGRÁFICA}

O puerpério é o período pós-parto que se inicia após o período de Greenberg e apresenta um término indefinido. Didaticamente pode ser dividido em três períodos: $1^{\circ}$ ) imediato, que vai do $1^{\circ}$ ao $10^{\circ} \mathrm{dia} ; 2^{\circ}$ ) tardio, sendo do $11^{\circ}$ ao $45^{\circ}$ dia; e $3^{\circ}$ ) remoto, a partir do $45^{\circ}$ dia. Este período é marcado pela involução de todas as transformações ocorridas na gestação, retornando ao estado pré gravídico, seja das modificações locais, quanto das modificações sistêmicas. É marcado por alterações no âmbito físico, social e psicológico da mulher devidamente alteradas pela gravidez e parto. Também é no puerpério que acontece a aproximação e o fortalecimento da relação mãe-bebê através do contato e da amamentação, além do processo de adaptações às novas funções da maternidade, paternidade e demais papéis sociais que envolve o novo membro familiar (CONDELES PC, et al., 2019; MACIEL LP, et al., 2019). 
No período puerperal o corpo da mulher passa por diversas mudanças relacionadas a readaptação do organismo sem o bebê. Em geral essas readequações são decorrentes da nova rotina de cuidados com o recém-nascido e com os familiares envolvidos e estresse causado pelo parto. Vários destes fatores podem contribuir, isolados ou não, para o aparecimento de transtornos no domínio físico e/ou mental da puérpera (CONDELES PC, et al., 2019).

Em relação às transformações físicas no corpo da mulher neste período, algumas são características, como a destruição dos remanescentes do hímen, alterações morfológicas do orifício externo do colo uterino, presença de secreções no canal vaginal, vagina edemaciada, manutenção de estrias gravídicas, relaxamento da musculatura abdominal e perineal, dificuldades na deambulação e no repouso, diástase, cefaleia, dificuldades na lactação devido a presença de fissuras e infecções nas mamas (SANTOS EKA, 2013; MELO SB, et al., 2018).

As transformações psíquicas por sua vez, podem interferir diretamente na saúde da mulher no período puerperal, necessitando cuidados especiais à mesma, devido aos riscos que possa ser exposta. A Depressão Pós-Parto (DPP) é um exemplo de alteração na saúde mental de mulheres neste período, sendo caracterizada por humor disfórico, distúrbios do sono, modificações no apetite, presença constante de fadiga e culpa excessiva; desinteresse pelo bebê, aumento da irritabilidade e da ansiedade; desmotivação, prolongamento da tristeza e baixa autoestima, refletindo em episódios de choro; sensação de incapacidade para assumir a maternidade, e, por fim, pensamentos suicidas.

Outros exemplos de transformações psíquicas, são o Baby Blue, que é um estado similar ao da DPP, no entanto os sintomas são caracterizados como mais brandos, geralmente relacionados à melancolia pós-parto e pode atingir entre $50 \%$ a $70 \%$ das mulheres. Já a Psicose Pós-Parto, é apresenta menor prevalência, sendo considerado um distúrbio psiquiátrico de maior gravidade, nos quais envolve episódios intensos e duradouros de psicose, no qual há necessidade de acompanhamento contínuo com profissionais habilitados e até mesmo internação hospitalar (SANTOS EKA, 2013; MELO SB, et al., 2018).

Vale ressaltar que os transtornos mentais nos qual as puérperas podem ser acometidas, interferem não apenas em sua rotina, mas também nas relações familiares como um todo, uma vez que os seus membros integrantes podem ser afetados diretamente, como mãe e filho, esposa e marido, assim como as demais relações existentes e criadas em âmbito familiar. Portanto, a perturbação do equilíbrio individual da puérpera tem um potencial importante de repercutir de diferentes formas e muitas dessas, podem gerar um esgotamento físico e mental delas, principalmente e dos demais envolvidos na família (CARVALHO GM, et al., 2019).

As práticas integrativas em saúde são utilizadas no cuidado, manutenção e recuperação da saúde, com grande influência de tradições, costumes e saberes milenares, apresentando grande resolutividade e efetividade na saúde do indivíduo. Por serem práticas simples, baratas, acessíveis e que auxiliam no autocuidado, se enquadram num modelo assistencial holístico no qual há um equilíbrio entre ciência, tecnologia e humanização. Tais práticas podem se integrar substancialmente a saúde da mulher na assistência no puerpério, tornando sua participação ativa durante essa fase ao proporcionar à mesma 0 suporte físico, social e emocional, além de contribuir no desenvolvimento de sua autonomia e cidadania (BORGES MR, et al., 2011).

De acordo com Borges MR, et al. (2011), uma das vantagens que se pode destacar em relação às práticas integrativas, é que elas são de baixo custo. No mais, os métodos terapêuticos considerados não convencionais são práticas milenares utilizadas por diversos povos e culturas no cuidado, manutenção e recuperação da saúde. Com uma fundamentação muitas vezes associada à tradição e aos costumes, o uso dessas práticas populares demonstra grande aceitação pela resolutividade e efetividade nas suas aplicações (BORGES MR, et al., 2011).

Segundo a Organização Mundial da Saúde (2013) houve aumento significativo na utilização das PICS devido aumento dos custos dos serviços de saúde, levando o usuário a procurar formas alternativas de cuidado, considerando o aumento da prevalência de doenças crônicas, degenerativas e incapacitantes; retorno da importância de um cuidado humanizado e holístico; e também tratamentos que proporcionem qualidade de vida quando não há possibilidade de cura (AMADO DM, 2017). 
As evidências científicas na literatura demonstram que de modo geral as PICS contribuem positivamente para o puerpério, visto que são métodos capazes de auxiliar a mulher de forma efetiva no restabelecimento físico e mental. Dentre os vários benefícios para a assistência, alguns podem ser elencados: manejo e alívio da dor, indução e progressão do trabalho de parto; e recuperação emocional com a redução da ansiedade, tristeza, melancolia, indisposição e estresse. Outros os benefícios físicos podem ser observados como a reduções da constipação intestinal, acúmulo de flatus, náuseas, vômito, edemas e cólicas (REIS BR, et al., 2019; LEHUGEUR D, et al., 2017; MUÑOZ SE, et al., 2016).

Incorporadas à Atenção Primária à Saúde, as PICS puderam proporcionar uma assistência individualizada à puérpera ao promover ou recuperar saúde por meio da medicina alternativa (BRASIL, 2012; 2018). Dentre as várias terapias, a utilização de plantas medicinais e aromaterapia; a prática chinesa Lian Gong, a meditação, e a técnica de Shantala podem ser elencadas. As diversas formas de aplicação dessas PICS podem ser vistas, como por exemplo, pelo cultivo de hortas domésticas e/ou adquiridas em mercados e feiras à preços acessíveis. Já a utilização de plantas medicinais, a realização das práticas como meditação, shantala e Lian Gong, há possibilidades de serem realizadas de forma gratuita, uma vez que aprendam a técnica adequada, podendo ser praticadas em espaços familiares e dependendo apenas da motivação para executálas (FARIAS KVO, et al., 2019).

Em relação ao uso de plantas medicinais, o Brasil possui uma grande biodiversidade, estimada em mais de 2 milhões de tipos de plantas, animais e microrganismos, tornando-o como um dos maiores detentores da diversidade biológica mundial $\mathrm{A}$ utilização desta diversidade pelo homem vem de tempos imemoriais, sendo importante para a manutenção da saúde no avanço de descobertas de novos fármacos, trazendo vantagens e avanços para a sociedade na área da saúde. Seus benefícios podem ser vistos agindo em sintomas agudos e até em doenças graves e crônicas. Vale destacar que o uso de plantas para fins medicinais não isenta o risco de efeitos adversos e prejudiciais que tal flora possa ocasionar. Logo, é importante seu uso consciente e com orientações profissionais a fim de informar e entender sobre os riscos e benefícios à cada usuário (BRASIL, 2012).

Em geral as plantas medicinais são utilizadas na forma de chás, e as orientações de uso de cada erva devem incluir as indicações, contraindicações e a forma de preparo (infusão ou decocção) que dependerá de sua apresentação (folhas, flores, frutos, casca ou raiz). Durante a gestação, é comum a utilização destas plantas pelas gestantes com a finalidade de aliviar os sintomas causados pela gravidez. Geralmente, as indicações são vindas de mães e avós, porém algumas podem estar relacionadas à efeitos teratogênicos, abortivos e tóxicos, ressaltando assim a importância do uso consciente (CAMARGO FR, 2015).

No período puerperal as plantas também podem auxiliar a mulher, porém é válido ressaltar que devido a amamentação pode haver restrições em relação ao uso de algumas. A erva doce/funcho (Foeniculumvulgare), alfavaca (Ocimumbasilicum), hortelã pimenta (Menthapiperita), são exemplos de plantas que possuem efeitos galactogogos, favorecendo a secreção láctea e auxiliando a puérpera na produção láctea (BASTOS A, 2015).

A melissa (Melissa officinalis) ou erva cidreira, como é conhecida popularmente, possui efeitos que auxiliam em disfunções estomacais, são relaxantes e tratam insônia na puérpera. $O$ gengibre (Zingiberofficinale) também auxilia em disfunções estomacais e do trato respiratório, podendo associá-lo ao mel para combater resfriados, potencializando assim seus efeitos (BASTOS A, 2015). A camomila (Matricariachamomilla) atua no período puerperal com propriedades sedativa e calmante, combatendo sintomas de ansiedade e depressão. Seus efeitos também podem ser sentidos pelo bebê através da amamentação (BASTOS A, 2015).

A prática da aromaterapia busca por meio de Óleos Essenciais (OE's) restabelecer o equilíbrio corporal e mental causados pelos estresses diários, podendo ser utilizada em massagens cutâneas, inalações, escalda pés, diluição em água para banho de imersão, entre outros. Estes, são obtidos através de produtos naturais, puros e completos como plantas, raízes e caules, onde cada um apresenta propriedades e mecanismos de ação em diferentes partes do organismo, devendo ser utilizados cautelosamente de acordo com a necessidade de cada um e de forma particularizada para cada sintoma específico (SILVA MA, et al., 2019). 
Dentre os benefícios da aromaterapia destacam-se os efeitos antidepressivos, ansiolíticos, analgésicos, antissépticos e calmantes, que contribuem para melhorar a sensação de bem-estar e recuperação pós-parto. Ressalta-se a importância do uso correto e consciente desta prática, uma vez que podem causar efeitos indesejáveis com seu uso prolongado, verificados por náusea, cefaleia, alergia e irritação na pele (PAGANINI T, SILVA FY, 2014; SILVA MA, et al., 2019). Nos casos da utilização dos OE's em massagens cutâneas é recomendado que seja diluído a $1 \%$ e seu uso mais interessante é quando há diluição em uma base, preferencialmente de óleos vegetais, devido a sua grande compatibilidade com a pele humana, minimizando assim qualquer irritação ou sensibilidade (AMARAL F, 2017; COSTA AF, 2019).

A utilização de OE's no puerpério pode ser visto pelo o uso da erva doce (Foeniculumvulgare) e anis estrelado (Illiciumverum), que possuem efeitos galactagogos, e auxiliam na produção de leite materno. Já a hortelã verde (Menthaspicata) contribui para a diminuição da produção excessiva de leite e também pode ser utilizado em forma de massagens nas mamas. A lavanda (Lavandula), o limão siciliano (Citruslemon) e a laranja doce (Citrussinensis) são conhecidos por seus efeitos analgésicos e ansiolíticos, proporcionando alívios nas dores, na tristeza e na melancolia, melhorando, portanto, o bem-estar da puérpera. É recomendado para estes últimos compomentes dos OE's, massagem, inalações e escalda-pés (COSTA AF, 2019). Por fim, apalmarosa (Cymbopogonmartinii) apresenta propriedades antissépticas, bactericidas, cicatrizantes, além de estimulantes e tonificantes à mulher, sendo útil no trabalho de parto e no puerpério, uma vez que é considerado um excelente tônico uterino (PRICE S e PRICE L, 2012).

A prática chinesa Lian Gong significa "prática" ou "exercício". É baseada em trabalho corporal, respiratório e mental, de exercícios que podem ser realizados em alguns minutos na postura em pé, com envolvimento de músicas criadas para tal prática. Esta PIC's foi criada como resultado da milenar na medicina tradicional chinesa e massagem terapêutica com base em exercícios de vários estilos de artes marciais, extraindo deles os melhores movimentos.

Utiliza movimentos que causam alongamento com tração, através de técnicas de fortalecimento harmonioso do corpo, desenvolvendo habilidades, persistência e simultaneamente a respiração consciente. Entre os benefícios da prática do Lian Gong, é observado o fortalecendo dos tônus musculares, estimulação da movimentação das articulações, benefício ao sistema circulatório. Desta forma, contribui, ao atuar no corpo humano de forma integral, no alivio das dores corporais relacionados à má postura, potencializa a melhor qualidade do sono e humor, e, consequentemente, reduz a necessidade do uso de medicamentos alopáticos (FIDALGO J, 2001; SILVA SCSB, et al., 2019).

Segundo estudos na área da saúde da mulher e ciclos reprodutivos, o Lian Gong é utilizado no puerpério como forma de preservar e melhorar a saúde da mesma, assim como prevenir o envelhecimento prematuro do corpo, uma vez que tal prática é encontrada virtudes fundamentais que apresentam fatores preventivos, corretivos e fortalecedores da energia vital. De forma mais pontual, alguns autores fazem menção aos benefícios que a prática de Lian Gong ao oferecer à mulher no puerpério, o alívio das dores musculares, da indisposição, contribui também para as reduções de insônia, edema, alterações de humor e dispneia (HIDALGO NR, et al., 2018).

Para a execução da prática do Lian Gong recomenda-se que tal técnica seja introduzida ainda no prénatal, uma vez que a equipe de saúde poderia disponibilizar maior tempo de contato e vínculo com a gestante, possibilitando a inserção e domínio dos movimentos no ensino à mesma, além de poder usufruir de seus benefícios já durante a gestação (BRASIL, 2005).

Outra PIC's que pode ser aplicada às puérperas é a meditação, uma prática presente no budismo, relacionada ao bem-estar psicoemocional através da concentração com foco na mente e controle sobre seus pensamentos. A meditação envolve o controle da respiração e a plena atenção, podendo ser realizada de forma dinâmica no decorrer do dia, durante atividades comuns, ou de forma estática, onde se reserva um tempo e espaço dedicados exclusivamente para tal técnica (VOTTO GG e CARVALHO HCW, 2019). Alguns benefícios encontrados com a meditação no período puerperal são o combate a ansiedade e depressão, redução dos níveis de percepção de estresse, redução da insônia, equilíbrio dos sistemas endócrino e imunológico, controle da pressão arterial sistólica, redução da dor e melhora da concentração e foco mental (LEMOS KCV, 2014; OLIVEIRA D, 2016). 
Recomenda-se que a gestante se aproprie da técnica de meditação durante o pré-natal, se beneficiando para o alívio de sintomas comuns durante a gravidez, como as variações do humor, ansiedade, estresse, medo, depressão, dores lombares e dispneia (BRASIL, 2005). Desta forma, a meditação ao integrar a rotina da gestante apresentará forte contribuição no puerpério, ao reduzir os efeitos indesejáveis no período pósparto, exemplificados por estados depressivos, melancolia e transtornos psicoemocionais comuns nesta fase (OLIVEIRA D, 2016).

A massagem Shantala é uma técnica indiana que atua na superfície subcutânea, sendo uma terapia que está entre as mais antigas e tradicionais, a partir de toques e leves manipulações pela mãe no corpo do bebê. É utilizada após o nascimento, como forma de continuidade da relação e do contato íntimo entre o binômio. Vale mencionar que a Shantala não é uma massagem unicamente terapêutica, mas uma técnica que possibilita ao recém-nascido suportar e/ou superar a transição de um ambiente interno totalmente protegido para um ambiente externo desconhecido (CAMPADELLO P, 2006).

Por fim, a técnica de Shantala é utilizada associada a OE's diluídos e previamente aquecidos pela fricção das mãos, potencializando o efeito dessas práticas integrativas. Deve-se orientar a mãe no preparo desta massagem, assim como em sua apropriação para que os vários cuidados necessários possam ser otimizados, proporcionando assim um sinergismo entre o binômio (CAMPADELLO P, 2006). Entre seus benefícios da Shantala, destaca-se a sensação de relaxamento e bem-estar ao bebê ou criança, 0 auxílio ao desenvolvimento dos sistemas, circulatório, respiratório, digestivo e linfático ao ativar a circulação sanguínea local, dilatando os vasos periféricos, e auxiliando o retorno venoso. Essas massagens também atuam na regulação da pressão arterial e aumenta a distribuição de sangue nos órgãos internos, músculos e tecidos. No sistema imunológico atua aumentando o número de plaquetas, hemoglobinas, células vermelhas e brancas, favorecendo assim o funcionamento do metabolismo (CAMPADELLO P, 2006; CARNEIRO DRC, et al., 2020).

Essa pesquisa propôs identificar e averiguar como as práticas integrativas e complementares em saúde, comuns e acessíveis, podem propiciar benefícios ao binômio mãe-filho no período puerperal. Contudo, se faz necessário reconhecer suas limitações, uma vez que apresentou reduzido escopo literário atualizado em virtude do baixo número de trabalhos publicados com a temática proposta. A maioria dos trabalhos científicos e pesquisas publicadas são direcionadas à gestação da mulher. Logo, é imprescindível o desenvolvimento e aplicação de estudos que tenham como objeto de estudo a assistência prestada à mulher durante o ciclo puerperal utilizando as PICS, a fim de possibilitar a maior qualificação dos serviços de atenção à saúde da mulher e qualidade de vida a elas.

\section{CONSIDERAÇÕES FINAIS}

As PICS são opções reais para proporcionar uma assistência individualizada à puérpera ao promover ou recuperar saúde por meio da medicina alternativa. Dentre as várias terapias, a utilização de plantas medicinais e aromaterapia; a prática chinesa Lian Gong, a meditação, e a técnica de Shantala puderam ser elencadas e suas diversas formas de aplicação possibilitam uma transformação saudável e gradativa diante das diversas alterações sofridas pela mulher entre os períodos de gestação e puerpério. Os benefícios proporcionados pelas PICS à puérpera, contempla, de uma forma geral, o binômio mãe/filho e podem ser vistos por benefícios como alívio de dores, desconfortos, cansaço e disfunções orgânicas, alívio de ansiedade e tristeza, frequentes nesse período.

\section{REFERÊNCIAS}

1. AMADO DM, et al. Política Nacional de Práticas Integrativas e Complementares no Sistema Único de Saúde 10 anos: avanços e perspectivas. Journal of Management \&Primary Health Care, (2017) 8(2), 290-308.

2. AMARAL F. Técnicas de aplicação de óleos essenciais. São Paulo: Cengage Learning, 2017.

3. BASTOS A. Plantas Medicinais Brasileiras Aplicadas aos Princípios da Medicina Chinesa. E-book. 2015.

4. BORGES MR. As práticas integrativas e complementares na atenção à saúde da mulher: uma estratégia de humanização da assistência no hospital Sofia Feldman. Revista Mineira de Enfermagem: REME, 2011; 1(15): 105113.

5. BRASIL. Cadernos de atenção básica: Práticas Integrativas e Complementares. Brasília: Ministério da Saúde, 2012; $156 \mathrm{p}$. 
6. BRASIL. Lei No. 8080/90, de 19 de setembro de 1990. Brasília: DF, 1990.

7. BRASIL. Ministério da Saúde. Portaria no 91 , de 10 de janeiro de 2007. Regulamenta a unificação do processo de pactuação de indicadores e estabelece os indicadores do Pacto Pela Saúde, a serem pactuados por Municípios, Estados e Distrito Federal. Diário Oficial [da] União. Brasília, DF, 2007.

8. BRASIL. Ministério da Saúde. Secretaria de Atenção à Saúde. Departamento de Atenção Básica. Plantas medicinais e fitoterapia. Brasília, 2012; 1.

9. BRASIL. Ministério da Saúde. Secretaria de Atenção à Saúde. Departamento de Atenção Básica. Política Nacional de Práticas Integrativas e Complementares no SUS - PNPIC-SUS. Ministério da Saúde, Secretaria de Atenção à Saúde, Departamento de Atenção Básica. - Brasília: Ministério da Saúde, 2006. 92 p. - (Série B. Textos Básicos de Saúde).

10. BRASIL. Ministério da Saúde. Secretaria de Atenção à Saúde. Departamento de Ações Programáticas Estratégicas. Área Técnica de Saúde da Mulher. Pré-natal e Puerpério: atenção qualificada e humanizada - manual técnico. Ministério da Saúde, Secretaria de Atenção à Saúde, Departamento de Ações Programáticas Estratégicas - Brasília: Ministério da Saúde, 2005. 163 p. color. - (Série A. Normas e Manuais Técnicos) - (Série Direitos Sexuais e Direitos Reprodutivos - Caderno no 5).

11. BRASIL. Ministério da Saúde. Secretaria-Executiva. Secretaria de Atenção à Saúde. Glossário temático: práticas integrativas e complementares em saúde / Ministério da Saúde, Secretaria-Executiva, Secretaria de Atenção à Saúde. - Brasília: Ministério da Saúde, 2018. 180 p.

12. BRASIL. Ministério da Saúde. Diretrizes operacionais dos pactos pela vida, em defesa do SUS e de gestão Brasília, DF, 2006b. (Série A. Normas e Manuais Técnicos).

13. BRASIL. Ministério da Saúde. Pacto pela saúde Brasília, DF, 2006a.

14. CAMARGO FR. Promoção da saúde Materno-Infantil: grupo reflexivo sobre o uso de plantas medicinais e medicamentos fitoterápicos na gravidez e lactação, 2015; 38.

15. CAMPADELLO P. Shantala: massagem, saúde e carinho para o seu bebê. Massagem, Saúde e Carinho para o seu bebê. São Paulo: Madras, 2006; 162 p.

16. CARNEIRO DRC, et al. A Shantala na atenção primária à saúde para promoção do cuidado infantil: relato de experiência. RevEnferm UFPI, 2020;9:e8794.

17. CARVALHO GM, et al. Transtornos mentais em puérperas: análise da produção de conhecimento nos últimos anos. Brazilian Journal of Health Review, 2019; 2(4): 3541-3558.

18. CONDELES PC, et al. Qualidade de vida no período puerperal: importância e satisfação. Rev Rene, $2019 ; 20: 1-7$.

19. COSTA AF. Aromaterapia na gestação e pós-parto. Instituto Brasileiro de Aromatologia/LAZLO. 2019, 13p. e-Book.

20. CUNHA AC, et al. Avaliação da atenção ao pré-natal na Atenção Básica no Brasil. Revista Brasileira de Saúde Materno Infantil, 2019; 1806-9304.

21. FARIAS KVO, et al. Projeto de extensão "Bem Gestar". Revista Em Extensão, 2019; 18(1): 165-175.

22. FIDALGO J. Manual do Lian Gong. Folha Online, 2001; 1-23.

23. HIDALGO NR, et al. AplicacióndelLian Gong Shi Ba Faentrabajadores y jubilados enlaEscuelaLatinoamericana de Medicina. Panorama Cuba y Salud, 2018; 13(1): 31-35.

24. LEHUGEUR D, et al. Manejo não farmacológico de alívio da dor em partos assistidos por enfermeira obstétrica. Revenferm UFPE, 2017; 11(12): 4929-4937.

25. LEMOS KCV. Meditação baseada em mindfulness e o método Feldenkrais® como terapias complementares no SUS: A Implementação da Política Nacional de Práticas Integrativas e Complementares no Instituto Nacional de Traumatologia e Ortopedia (INTO) Sob a Perspectiva dos Usuários. Dissertação (Mestrado em Psicossociologia). Programa de Pós-Graduação em Psicossociologia de Comunidades e Ecologia Social. Universidade Federal do Rio de Janeiro. Rio de Janeiro, 2014; $131 \mathrm{f}$.

26. MACIEL LP, et al. Mental disorder in the puerperal period: risks and coping mechanisms for health promotion. Revista de Pesquisa: Cuidado é Fundamental Online, 2019; 11(4): 1096-1102.

27. MELO SB, et al. Depressive symptoms in postpartum women at Family Health Units. Revista Brasileira de Saúde Materno Infantil, 2018; 18(1): 163-169.

28. MUÑOZ SE, et al. A experiência de lasmujeresenel alivio deldolordel parto: conocimiento y utilidade de las terapias complementarias y alternativas. Matronas Prof. Barcelona, 2016; 17(2): 51-58.

29. OLIVEIRA D. Variabilidade da frequência cardíaca, dos níveis de stress e pressão arterial em adultos e idosos resultantes da prática de yoga. 2016. 38 f. Trabalho de conclusão de curso (Licenciatura - Educação Física) Universidade Estadual Paulista, Instituto de Biociências de Rio Claro, 2016.

30. ORGANIZAÇÃO MUNDIAL DE SAÚDE (2013). WHO traditionalmedicine strategy: 2014-2023. WHO Library.

31. PAGANINI T, SILVA FY. O uso da aromaterapia no combate ao estresse. Arq. Ciênc. Saúde Unipar, 2014; 18(1): 4349.

32. PRICE S, PRICE L. Aromatherapy for Health Professionals. 4ํㅡㄹition. Churchill Livingstone, 2012; 396p.

33. REIS BR, et al. C\&D-Revista Eletrônica da FAINOR, 2019; 12(3): 677-686.

34. SANTOS EKA. Curso de Especialização em Linhas de Cuidado em Enfermagem: Enfermagem na Atenção à Saúde da Mulher, do Neonato e à Família: Alojamento Conjunto: Universidade Federal de Santa Catarina/Programa de PósGraduação em Enfermagem, 2013; 131p.

35. SILVA MA, et al. Aromaterapia para alívio da dor durante o trabalho de parto. Revista de Enfermagem: UFPE online, 2019; 2(13): 455-463.

36. SILVA SCSB, et al. A aplicação da aromaterapia como método de alívio da dorem gestantes: uma revisão integrativa. Vittalle - Revista de Ciências da Saúde, 2019; 31(1): 61-73.

37. VALADARES C. Ministério da Saúde inclui 10 novas práticas integrativas no SUS. Rio de Janeiro-RJ. 2018.

38. VOTTO GG, CARVALHO HCW. Bem-estar psicológico e meditação: um estudo associativo. Estudos Interdisciplinares em Psicologia, 2019; 10(3): 60-75. 